\section{Sonja Cerepnalkovska ${ }^{1}$ Kristina Bombas Georgievska Dejan Ristić}

\title{
GLOBAL PROOF FOR CONSISTENT QUALITY - QUALITY CONSTRUCTION PRODUCT
}

Abstract: Development countries should create an environment for the successful integration of their economy into the European and international processes, and it is only possible with the harmonization of national legislation with the EU, and acceptance of European standards as national.

Why should the manufacturers use the harmonized standards if their application is voluntary?

The existence of unequal treatment on the market of construction products in the EU countries and the need of implementation of the equal treatment of the Declaration of performance - DoP and the principle of the system of Assessment and Verification of Constancy of Performance $(A V C P)$ of the construction products, were the basic reasons for adopting the new Regulation.

The authors would like to point, that the use of the harmonized standards, and referring to them, is the easiest and simplest method to guarantee product conformity with the basic requests of the relevant directive/regulative.

Keywords: Regulation, quality control, harmonization standards, AVCP, CE marking, DoP

\section{Introduction}

The existence of unequal treatment on the market of construction products in the EU countries and the need of implementation of the equal treatment of the Declaration of performance - DoP and the principle of the system of Assessment and Verification of Constancy of Performance (AVCP) of the construction products, were the basic reasons for adopting the new Regulation. The European parliament and Council on 9 March 2011 adopted REGULATION No 305/2011 - Construction products regulation (CPR), laying down harmonized conditions for the marketing of construction products and repealing Council Directive 89/106 EEC-CPD. The Regulation 305/2011 is applied from 1 July 2013.

In accordance with the regulation, construction works as a whole and in their separate parts must be fit for their intended use, taking into account in particular the health and safety of people involved throughout the life cycle of the works. Subject to normal maintenance, construction works must satisfy the basic requirements for construction works for an economically reasonable working life.

Construction products which are used in construction works have to meet the essential characteristics. The essential characteristics are defined in the harmonized

\footnotetext{
${ }^{1}$ Corresponding author: Sonja Cerepnalkovska Email: Cerepnalkovska.sonja@isrm.gov.mk
} 
technical specifications - harmonized standards and European technical assessment.

The basic requirements for construction works shall constitute the basis for the preparation of standardization mandates and harmonized technical specifications.

The Regulation No 305/2011 - Construction products regulation (CPR), is transposed into Law of Construction products in the Republic of Macedonia.

In this paper the authors would like to point out the difference between new Regulation 305/2011 and Directive 89/106.

\section{Quality infrastructure}

To persist in the global market, it is necessary on the internal (national) market to have established a quality infrastructure which consists of the activities of standardization, accreditation, conformity assessment, and metrology and market surveillance.

The standardization principles are the basis of the European quality infrastructure. Sometimes we do not notice the influence of standards on our everyday life, but the impact of standards in the economy can be far-reaching.

Figure 1, shows the basic connections and the central role of the standardization within the quality infrastructure.

These institutions allow sustainable development that can lead to full participation in international trade and can fulfil the technical requirements of the multilateral trade system.

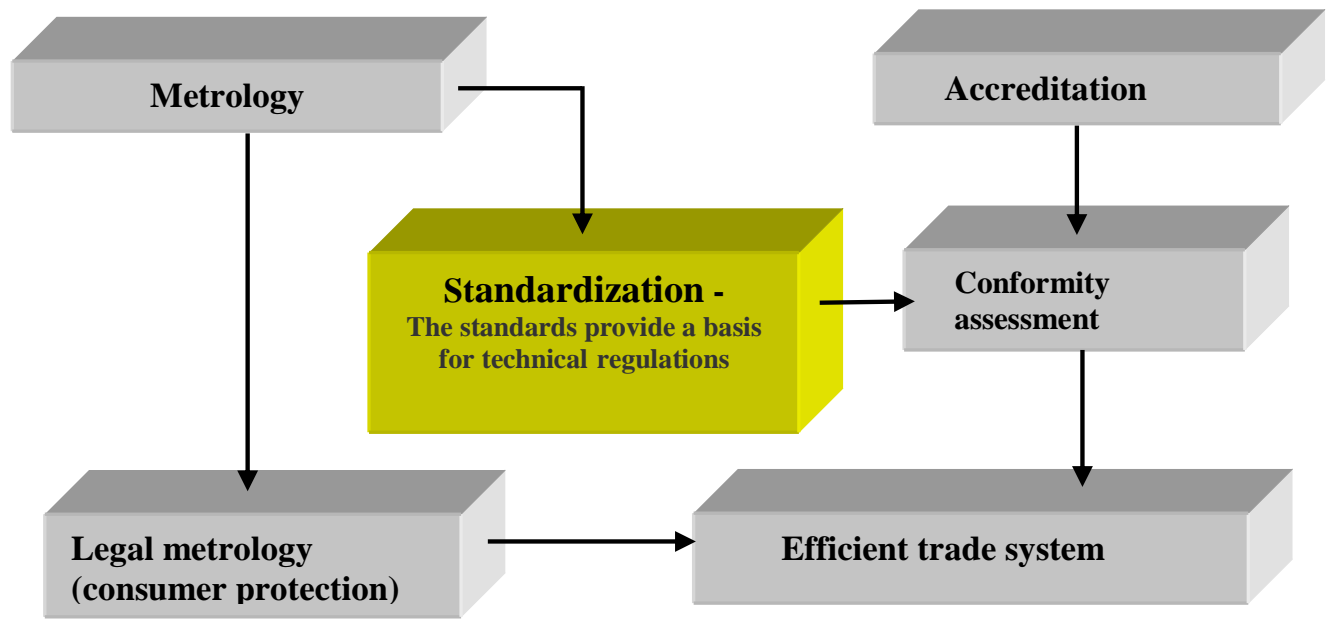

Figure 1. Link between metrology, standardization and conformity assessment

A priority of every government in every developing country is establishing and maintaining a basic infrastructure so that it can guarantee the safety, health and welfare of all its citizens - an adequate and safe provision of food, drinking water, healthcare and education availability, social safety, transportation, communication systems, etc. Only when all of this is set in place, even at its elementary level, the need of establishing an efficient trade system becomes the most important.

\section{The process of harmonization of the national technical legislation}

The process of harmonizing national technical legislation with European legislation is shown in figure 2 and is based on the transposition of the European Directives/Regulations of the New approach 


\section{Intermational Qualily Conference 13.}

$\mathrm{Q} \cup \mathbf{A} \| \mathbf{I I}$

of technical conformity and the Global member states have to transpose their approach for conformity assessment. national legislation. Unlike the directives, The directives represent the European legislation that cannot be directly applied; the regulations are directly applicable after its adoption by all member states.

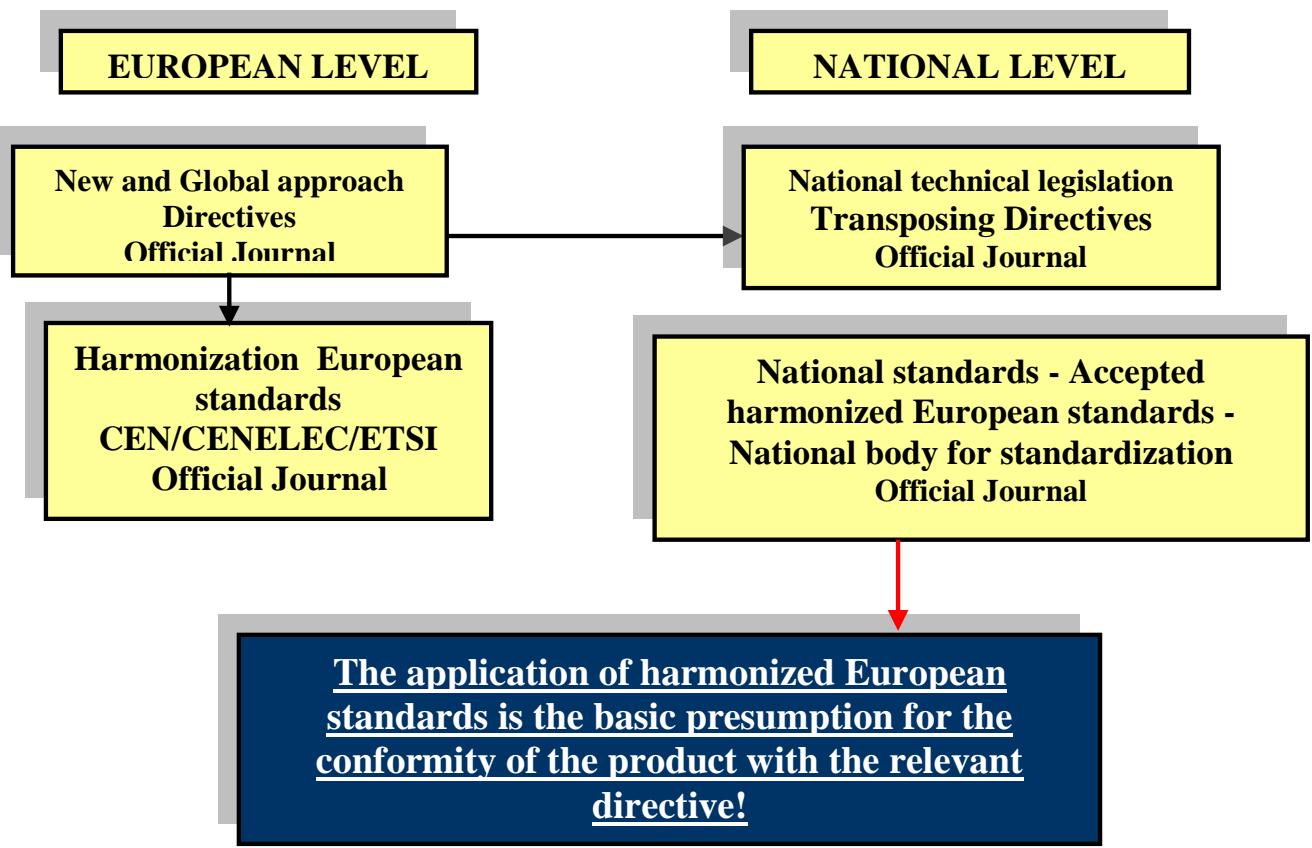

Figure 2. Presentation of the process of technical harmonization

The directives/regulations, based on the basic principle of the New and the Global approach, cover a large group of products and types of risk and determine only the basic requirements that the products have to fulfil.

\section{Regulation $305 / 2011$ in comparison to Directive 89/106 EEC has more changes and news}

1. One of the news that concerns the CPR is that CPR identified seven Basic Works Requirements (BWRs):

1) BWR 1: Mechanical resistance and stability, 2) BWR 2: Safety in case of fire, 3) BWR 3: Hygiene, health and environment, 4) BWR 4: Safety and accessibility in use, 5)
BWR 5: Protection against noise, 6) BWR 6: Energy economy and heat retention and 7) BWR 7: Sustainable use of natural resources. The difference is just the seventh condition, which was not contained in the Directive. The construction works must be designed, built and demolished in such a way that the use of natural resources is sustainable and in particular ensure the following: (a) reuse or recyclability of the construction works, their materials and parts after demolition; (b) durability of the construction works; (c) use of environmentally compatible raw and secondary materials in the construction works.

2. Different construction products influence differently the safety of the building. The importance of the product is evaluated according to the consequences that an unsuitable product would have on the 
construction. Taking into account the importance of the product in relation to its essential characteristics there are five different levels of systems of assessment and verification of constancy of performance (AVCP), which have been defined using the numbers $1+, 1,2+, 3$ and 4 .

The "System 1+" is the most demanding and is designed for the products which have the most influence on fulfillment of essential requirements which contribute to the mechanical resistance and stability and/or fire resistance of works. The System 4 is the least demanding and is designed for products with minor influence on health and safety.

3 . In certain cases there is no obligation for the manufacturer to issue the declaration of performance. Basically, if there is a specific order, or the construction product is made on site, the obligation for the declaration of performance and ' $\mathrm{CE}$ ' marking can be omitted.

4. The Regulation has many detailed requests related to Declaration of Performance. After carrying out all the prescribed procedures, the manufacturer must prepare the Declaration of Performance by himself. Declaration of Performance is about the essential characteristics of the construction product, in accordance with the harmonized technical specification for placing of the product on the market. The new form of the Declaration of Performance requires more information related to the identification of the relevant product and the manufacturer. The performance should be stated in the declaration and the form and content of the declaration is regulated by the Delegated Act of the European Commission No. 574/2014.

5. Further on, with new Regulation the principles for preparation and adopting of the European Assessment Document - EAD and its contents are regulated. This applies to all the construction products that are not covered or are not covered completely with the harmonized standard and in which the performances of their essential characteristics cannot be fully assessed by the harmonized standard. In that case, on request of the manufacturer, the Technical Assesment Body - TAB, together with the organisation of TABs (EOTA) prepares and issues European Assesment Document EAD. Further on, based on the European Assesment Document - EAD, and on request of the manufacturer, European Technical Assesment - ETA is issued by the Technical Assessment Body, established in accordance with the procedures laid down in the provisions of the Regulation.

6. In connection with the REACH Regulation (Registration Evaluation Authorization and Chemicals Restriction), the information that imply the dangerous matters within the construction products will be provided together with the Declaration of Performances.

7. The economic operators are defined as manufacturers, importers, distributers or authorized representatives. Having this in mind, it is clear that the importers have defined responsibility for the products that they trade. If this is not respected, the action leads to violation of the Regulation.

8. The European bodies for technical approvals will be re-nominated in the bodies for technical assessment, but this is not an automatic process.

9. The necessary market surveillance procedures for construction products are clearly defined in the Regulation. In this way the European Commission wants to improve the policy and implementation of the Regulation.

In the Republic of Macedonia, the Ministry of economy is in charge for the process of transposing the Regulation. The Standardization Institute of the Republic of Macedonia - ISRM is responsible for adopting all the harmonized European standards as national, Macedonian standards. On request of the Ministry of economy, ISRM submits a list of adopted harmonized standards to the Ministry and the Ministry further on publishes the list in the Official Gazette of the Republic of Macedonia. However, there are many additional 


\section{Intermational Qualitity Conference 1 :}

activities for implementation of this Law left to the authorities and the commercial subjects.

\section{Conclusion}

Standards are amongst the most important tools used by the managing structures within the organizations.
It is important to note that the producers with an established quality management system will not automatically assure the presumption that their product conforms to the "CE" marking. The relevant directives of the New approach will stipulate correctly and entirely the direction for the conformity assessment.

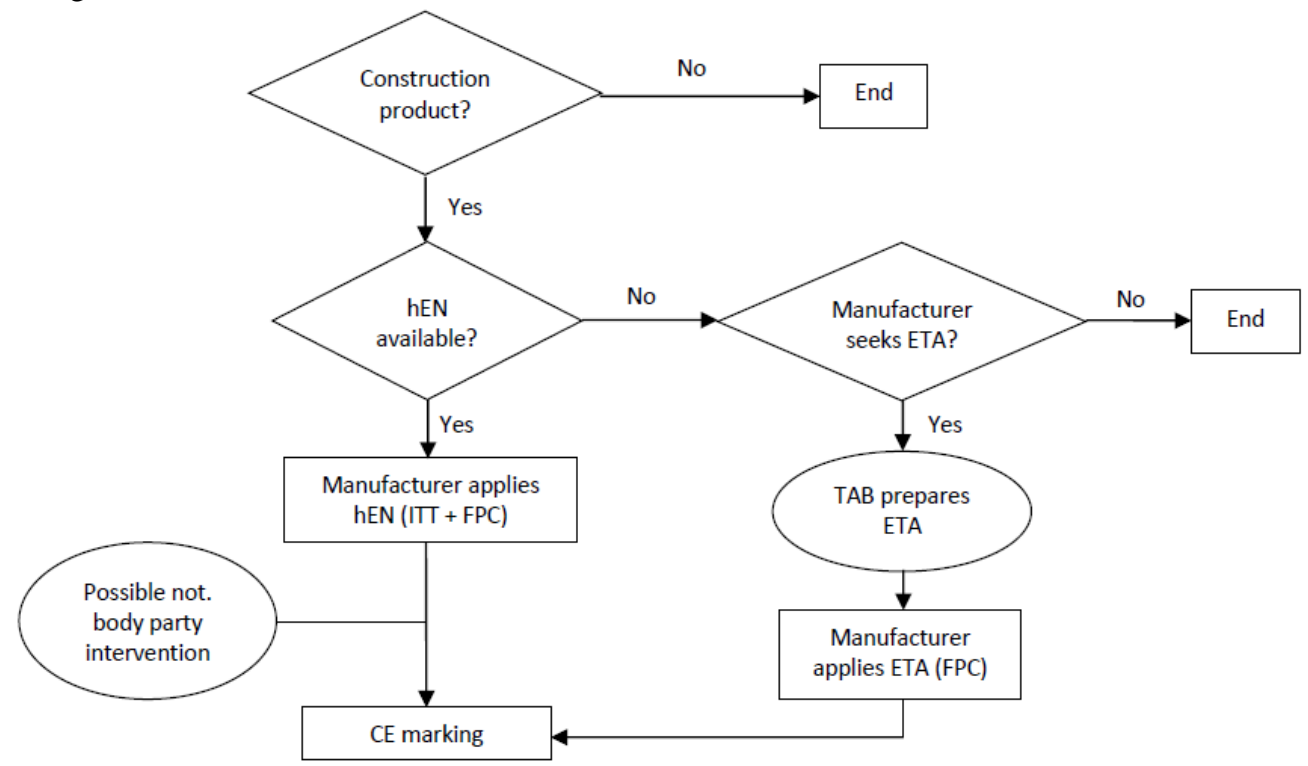

Figure 3. Flowchart for producer

The standards are also a tool when we shape, examine and certify the product; and, not only the product, but also technological or production systems or service systems. The meaning of standardization grows with the growth of the global market and the increase in choice of products and services.

The authors would like to conclude that implementation and reference to harmonized standards is the easiest and simplest method to guarantee product conformity with the basic requests of the relevant regulation. In figure 3-flowchart shows, in somewhat simplified form, the procedure for deciding whether a product falls under the scope of the CPR and, if so, what the manufacturer has to do.

The movement for quality in the world is a part of the efforts of global and European business to adjust to the changes in the global market, always noting that quality stays a fundamental way of making every business everywhere in the world.

\section{"Quality cannot be a goal, but a means for achieving the goal - and that is the quality of life" Warning by Ralph Nader}




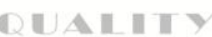

References:

EU Commission (September 2002). Guidance Paper B, The definition of Factory Production Control in Technical Specification for Construction products.

EU Commission (27 May 2004). Guidance Paper D, CE Marking under the Construction Products Directive

Official Journal of the European Union (4.4.2011). Regulation (EU) No 305/2011 of European Parliament and of the Council of 9 March 2011

BSI (December 2012). Guidance Note on the Construction Products Regulation

\section{Sonja Cherepnalkovska,}

Standardization Instituteof Republic of North Macedonia,

Skopje,

Republic of North Macedonia cerepnalkovska.sonja@isrm.gov.mk

\section{Kristina Bombas}

Georgievska

GEING Krebs und

Kiefer International and others, Ltd,

Skopje,

Republic of North

Macedonia

kristina@geing.com.mk
Dejan Ristić

Standardization Instituteof Republic of North Macedonia, Skopje,

Republic of North

Macedonia risticdejan972@gmail.com 